\title{
Kyrgyz Republic: Joint Staff Assessment of the Poverty Reduction Strategy Paper Annual Progress Report
}

The attached Joint Staff Assessment (JSA) of the Poverty Reduction Strategy Paper Progress Report for the Kyrgyz Republic prepared by the staffs of both the World Bank and IMF, was submitted with the member country's Poverty Reduction Strategy Paper (PRSP) or Interim PRSP (IPRSP) to the Executive Boards of the two institutions. A JSA evaluates the strengths and weaknesses of a country's poverty reduction objectives and strategies, and considers whether the PRSP or IPRSP provides a sound basis for concessional assistance from the Bank and Fund, as well as for debt relief under the Enhanced Heavily Indebted Poor Countries (HIPC) Debt Initiative. The Boards then decide whether the poverty reduction strategy merits such support.

To assist the IMF in evaluating the publication policy, reader comments are invited and may be sent by e-mail to publicationpolicy@imf.org.

Copies of this report are available to the public from

International Monetary Fund • Publication Services

$70019^{\text {th }}$ Street, N.W. • Washington, D.C. 20431

Telephone: (202) 623-7430 • Telefax: (202) 623-7201

E-mail: publications@imf.org • Internet: http://www.imf.org

Price: $\$ 15.00$ a copy

\section{International Monetary Fund Washington, D.C.}




\author{
INTERNATIONAL MONETARY FUND \\ AND THE INTERNATIONAL DEVELOPMENT ASSOCIATION
}

\title{
KYRGYZ REPUBLIC
}

\section{Joint Staff Assessment of the Poverty Reduction Strategy Paper Annual Progress Report}

\author{
Prepared by Staffs of the International Development Association \\ and the International Monetary Fund \\ Approved by Shigeo Katsu and Gobind Nankani (IDA) \\ and Mohammad Shadman-Valavi and Michael Hadjimichael (IMF)
}

June 4, 2004

\section{OVERVIEW}

1. The National Poverty Reduction Strategy (NPRS) of the Government of the Kyrgyz Republic was discussed by the Boards of the International Monetary Fund (IMF) and the International Development Association (IDA) on February 21 and February 27, 2003, respectively. The Kyrgyz authorities have now prepared the first Progress Report on the implementation of the development strategy outlined in the NPRS.

2. The Progress Report builds on the broad policy priorities outlined in the NPRS. The three pillars of the NPRS aimed at (i) fostering economic growth and creating employment opportunities; (ii) improving efficiency and equity of social protection and human development; and (iii) improving governance, public sector efficiency and institutional and human capacity. In the JSA of the NPRS, the staffs endorsed these broad policy priorities to be consistent with the multi-dimensional nature of poverty alleviation and agreed that the policy action plan set forth in the NPRS was generally consistent with these three pillars. The Report describes developments in these priority areas, focusing on major policy and institutional underpinnings of the NPRS strategy, which is a much needed step forward in translating a very comprehensive NPRS to a more action-oriented strategy.

\section{Poverty Diagnosis}

3. The Report provides evidence of continued reduction in poverty. The Report discusses developments in a number of monetary and non-monetary poverty indicators. Poverty alleviation, as measured by monetary indicators, has been particularly impressive, with the poverty level falling to 40.8 percent in 2003, as compared to 44.4 percent in 2002 and 55.3 percent in 1999 , the year in which poverty levels reached their historical peak. Poverty developments have been particularly encouraging in the rural areas, where the majority of 
Kyrgyzstan's poor live, with a relatively larger reduction in the poverty level, and reductions in extreme poverty and expenditure inequality. By contrast, in urban areas both the level of extreme poverty and inequality increased. Non-monetary indicators such as food consumption by the three poorest quintiles support the contention that poverty has declined. However, challenges remain in improving the accessibility of basic services-e.g., there has been a small decline in accessibility of clean drinking water. The staffs also believe that the Kyrgyz infant mortality measure, which is reported to have declined by 0.5 percent in 2002 , is not a reliable indicator and needs to be supplemented by other performance indicators, such as the utilization of health services by pregnant women and by children under five years of age. ${ }^{1}$ Finally, important gaps in the Report are the absence of sanitation indicators, with increasing access to sewerage networks remaining a significant challenge, and gender specific poverty indicators. All in all, while the targeted reduction in poverty to 39 percent by 2005 seems more achievable now, a key challenge for sustained reduction remains the broadening of the sources of economic growth through continued reform and support to private sector development. This will also help alleviate the increasing urban poverty.

\section{The Report notes some efforts underway to improve the analytical basis of the} poverty diagnosis. The JSA of the NPRS had noted that the analysis of the relationship between employment generation and poverty reduction objectives was weak. This is being addressed by the commencement of an integrated budget and manpower household survey which include the establishment of a new benchmark and a more systematic monitoring of poverty, labor market and unemployment trends, and other dimensions of household welfare such as health, education, and access to network services, and allow for improved monitoring of the links between these policy dimensions. Data from the new survey will also allow a richer analysis of the impact of macroeconomic policies, sectoral policies and social policies on the evolution of poverty, all important gaps in the NPRS's poverty diagnosis identified in the earlier JSA.

\section{Priority Public Actions}

\section{Inadequate attention to analysis of recent developments and identification of key} policies for the period ahead is a serious shortcoming of the Report. In pursuing their poverty reduction strategy, in close cooperation with donors and domestic stakeholders, the Kyrgyz authorities have developed comprehensive and credible strategies in a wide range of areas. Progress in implementing such strategies has been mixed and, where necessary, the original strategy is being modified. However, the Report fails to discuss adequately this body of work as well as the key policy actions for the coming year. Thus, the Report fails to convey a clear impression of the state of play regarding the implementation of the poverty reduction strategy.

\footnotetext{
${ }^{1}$ A reduction in the birth rate would not contribute to a reduction in the infant mortality rate, as suggested by the Report, since the latter is measured in terms of per 1000 live births.
} 


\section{A. Macroeconomic Framework and Fiscal Choices}

6. The Report's updated medium-term macroeconomic framework is broadly appropriate with suitable progress on structural reforms. The Report's updated macroeconomic framework for 2004-07 is based on average growth of just under 5 percent per annum and annual inflation of about 4 percent. It is also consistent with the debt strategy, which requires curtailing the foreign financed public investment program (PIP), while generating real GDP growth based on private investment. The key sources of growth are to be the agricultural, industrial, construction and service sectors. The staffs believe that, given the expected decline in gold mining activity in the period ahead, with the largest reserves being depleted over the medium term, the growth strategy based on export diversification and promotion of private investment is necessary; however, its feasibility depends on how strongly the key governance and sectoral reforms will be implemented. In this regard, the analysis would have benefited from a more convincing exposition of the key elements behind the recent performance of the sectors identified as the sources of growth. The Report's discussion of real GDP developments in 2002 and 2003 focuses primarily on the role of exogenous factors that were of great significance, but a closer analysis of other developments in the important sectors would have helped identify the main reforms needed for the sectors to achieve the targeted growth rates. Specifically, efforts to address the challenges to raising the rate of growth of nongold exports will bear significantly on the feasibility of the medium-term overall growth projections. Similarly, the Report projects that investment will grow by $2 \frac{1}{2}$ percent over the medium term - with a major increase in private investments while public investments are being further rationalized - and that domestically produced goods will partly replace consumer goods imports. These projections would be more convincing if the Report had commented more effectively on the impact of the measures implemented thus far to improve the investment climate and identified the key steps contemplated in the period ahead.

\section{The staffs welcome the Report's explicit use of the medium-term budget} framework (MTBF) to match fiscal choices to NPRS priorities, but more work remains. In basing the fiscal choices on the MTBF, the Report makes progress in addressing the concern that the priorities identified in the NPRS may not have been affordable. Nevertheless, at this stage, the MTBF's focus is on the overall macroeconomic and fiscal framework and linkages among key sectoral policy actions, as identified in the NPRS, and the annual budgets are confined to the health, education and agricultural sectors. The Report should have noted these weaknesses and indicated how they will be addressed, as the MTBF process is advanced. Concerning the fiscal parameters, the Report includes appropriately ambitious revenue targets so as to allow suitable levels of spending on priority areas, particularly important in light of the debt strategy that strictly limits the foreign loan financed public investment program. The staffs particularly welcome the ongoing work on developing a new streamlined Tax Code noted in the Report and a simplified small business tax, both of which should help reduce the costs of tax compliance. However, the Report should have noted that the revenue targets will remain elusive without proper implementation of the new tax schemes introduced in 2003 (VAT in agriculture as well as the real property tax) and further strengthening tax administration. In line with the NPRS priorities, the Report targets spending on the health and education sectors, including all loan-financed project expenditure, to increase by $1 / 2$ percentage point and 1 percentage point of GDP, respectively, over the medium-term. However, the staffs believe 
that much work on program budgeting still remains to be done to better match anticipated policy outcomes to expenditure allocations. In this regard, the Report could have drawn on experience with program based budgeting in the health sector over the last several years.

\section{The Report would have benefited from a fuller discussion of recent budget} execution, especially for programs with a high poverty alleviation impact. The Report contains only a very sparse discussion of recent budget execution at the aggregate level. The staffs urge the authorities to better analyze budget execution data to determine whether recent spending has been in line with NPRS priorities and to provide the results of such analyses in future NPRS Progress Reports. The Report could also have discussed the difficulties that have been experienced with commitment control, which entailed the use of extraordinary measures to keep aggregate budget execution on track. The staffs commend the authorities for reflecting previously ministerial extra-budgetary funds in the budget, but urge that spending associated with such resources be urgently merged in the budgetary process.

\section{B. Structural and Sectoral Policies}

\section{The Report highlights significant ongoing work on governance reforms, but} would have benefited from a more balanced assessment of the progress thus far. The Report provides impressive detail regarding the steps taken to address governance concerns in a wide range of areas, including the judiciary, state financial management, civil service reform, corporate governance and anti-corruption activities. Key measures implemented in the last year include the completion of functional reviews of ministries and agencies, the introduction of measures to facilitate third-party arbitration, and significant progress towards automating the central Treasury. However, in light of the very poor ratings that the Kyrgyz Republic has received in recent cross-country surveys of corruption, the Report should have been more candid in recognizing that governance reform is a difficult process and that tangible improvements in this area remain to be achieved. ${ }^{2}$ In this regard it is encouraging that the work of the National Integrity Council (NIC), established in 2003, has become more focused with renewed support at the highest levels of government. Its composition, which brings together government, civil society and donors, should help build broad-based support for these difficult reforms. The staffs urge that in carrying out its future work, the NIC should seek to address concerns noted in the first JSA, notably the poor implementation of the procurement law, ways to increase the independence and effectiveness of the Chamber of Audit, and state capture by vested interests, which lies at the root of many governance problems. Finally, the staffs commend the authorities for increased attention to achieve tangible progress in strengthening local self governments and greater community involvement. For successful implementation, the staffs reiterate the need to focus on strengthening accountability and financial management at sub-national government level. In the short-term, the approach being piloted under the Village Investment Project, which is being implemented with assistance from the World Bank, offers considerable promise for channeling budgetary development grants for investments

\footnotetext{
${ }^{2}$ Transparency International's 2003 Corruption Perceptions Index ranks the Kyrgyz Republic $113^{\text {th }}$ in a sample of 130 countries.
} 
proposed by local authorities and civil society through the Aiyl Investment and Development Agency, which has appropriate procedures in place to ensure community consensus and efficient use of funds.

\section{Rapid development of the private sector will continue to underpin growth and} poverty reduction in the medium term. The NPRS had identified as a key objective improvements in the environment for development of the private sector, including the SME sector. To that end, financial sector reform, and improvements in the regulatory environment and the external trading environment were viewed as critical. The Report lists several important steps implemented in the financial sector as well as positive developments in key financial indicators. However, the financial sector remains weak and still not adequately developed to meet the financial intermediation requirements of the country. The staffs believe that the Report should have contained a better analysis of such remaining challenges and the key reforms being planned and/or already undertaken. Similarly, the Report notes that three annual investment matrices, listing various administrative reform measures, have been largely implemented. It also indicates that FDI grew by 28 percent in 2002 and 25 percent in 2003. But the staffs would caution against drawing firm conclusions from such gross data. This is not only because net FDI data and its composition suggests a less promising picture, but also because the results of recent investor surveys continue to demonstrate a large gap between the ongoing, major legislative reform and their implementation track record. The continuing decline in the number of reporting SMEs, as shown in Appendix 2, may also reflect the high burden of administrative barriers in the formal sectors of the economy. The Report should have undertaken a candid assessment of the effectiveness of the steps taken thus far, and highlighted the key steps necessary to make a lasting improvement in the investment climate in the year ahead. Recent agreements with Kazakhstan on transit trade suggest an improvement in the external trading environment. The Report should have noted these developments and proposed steps to monitor if the actual implementation in the period ahead is in line with the intent of the agreements.

\section{Sustaining agricultural growth and strengthening the livestock sector are critical} for the country's poverty reduction efforts in the medium term. This is recognized in the macroeconomic framework, which projects the agricultural sector to grow at an average rate of about $4 \frac{1}{2}$ percent over the medium-term. In light of the agricultural sector's large share in GDP and employment, and since the majority of the country's poor live in rural areas, such growth should contribute significantly to poverty reduction. At the same time, in light of other pressing NPRS priorities, public investment in the agricultural sector is projected to decline by over $1 / 2$ percentage point of GDP over the medium-term. Thus, the Report should have recognized that the higher growth rates are conditioned on commitment to accelerated implementation of the sectoral reform agenda - refraining from intervention in farmers' production and marketing decisions, vigorously promoting private service providers, and eliminating obstacles to the free flow of inputs and outputs. As noted in the Report, decreasing the interference of state agencies in business and economic activities is essential. The spirit of the recent Presidential Decree on further measures for land and agrarian reform does not point in that direction, and the failure to develop a more market oriented reform agenda would cast doubt on the feasibility of the agricultural sector growth projections. The staffs also believe that pastures and their sustainable management are critical for the very important livestock 
sector. The reported degradation of pastures is increasingly a threat in terms of soil erosion, land/mud slides and flooding. The Report should have noted that this is largely caused by the inefficient division of responsibility for pasture management among different levels of government - for instance with Aiyl Okmotus responsible only for the close-in pastures, these areas are increasingly overused and degraded because local herders cannot easily obtain grazing permits for more distant summer pastures.

12. The Report discusses suitably the needs in the education and health sectors. The Report builds on the comprehensive strategies presented in the NPRS and the staffs commend the authorities for their constructive proposals to improve the incentives of rural teachers. In this regard, the staffs recognize the low salaries of rural teachers, and the weaknesses in the implementation of the existing local salary supplement programs in rural schools due to local resource constraints. While addressing these problems through an appropriate resource transfer scheme, the staffs caution that these expenditures must be accommodated within the allocations for the education sector identified in the MTBF. The introduction of external examinations for university admission is also important and it should be followed up by the introduction of an independent testing agency to ensure that the high standards of professionalism established at the outset are maintained. The Report could also have usefully dwelt on the improved incentives for efficient management of primary and secondary schools that are being developed by the government. As regards the health sector, the Report presents a good overview of the progress on the legal framework for facilitating scaling up of the health reforms. This is important for the reforms as well as for promoting good governance.

\section{Predictable health care financing is central to sustaining reforms in the sector.}

Due to the problems in the timely allocation of general budget revenues (and to a lesser extent transfer of health payroll contributions) for various categories of the insured population over the last two years, the health care system has faced problems in ensuring the delivery of quality services. The staffs are concerned about implications of persistent underfinancing of the health budget, which should have contributed to the reported problems in access to health care services and the purported decline in the percentage of population insured (Appendix 2). These trends would have warranted both a more detailed analysis of the data at a disaggregated level and discussion on underlying causes for the deterioration. Against this background, the staffs welcome the planned increases in health sector financing in the Report, but recommend close monitoring and evaluation of the execution of the health budget to avoid problems discussed above.

\section{Recent efforts to improve social security through greater allocation and better} targeting of resources are commendable. The government's social protection strategy is based on providing meaningful assistance to those in greatest need. Thus, the recent increase in the Unified Monthly Benefit (UMB), reversing the earlier trend, and efforts to provide higher real benefit levels to a smaller group of households are appropriate, as are the efforts to experiment with new ways of targeting assistance more precisely, the plans to rationalize spending on "price privileges," and measures to supplement residential care for disadvantaged children with greater options through community based programs. The staffs also commend the authorities for making room for pension increases in the face of severe budgetary pressures and for ensuring that pensions are paid in a timely manner. However, the staffs reiterate their 
concerns expressed in the first JSA regarding plans to create a fully funded second-pillar pension component during the NPRS implementation timetable. ${ }^{3}$ The staffs welcome the initiatives to improve survey-based data on labor market behavior, as these will facilitate the development of policies that reduce disincentives to private sector development, freely functioning labor markets, and formal employment.

15. Reforms in the energy sector are critical for the country's development prospects.

The authorities have undertaken to eliminate the very large quasi-fiscal deficit in the electricity sector. This will require the elimination of technical and commercial losses. In this regard, the appointment of a Special Representative of the President with wide ranging authority to step up collections has seen some initial progress. Efforts on this front, such as disconnections of non-payers, must continue. In addition, the Government must take actions to make barter payments and off-sets illegal. Moreover, electricity tariffs will also need to be raised significantly, and it is important that the authorities announce the necessary tariff increases to implement the medium-term tariff policy at the earliest stage. Only with credible action on these fronts will it be possible to attract to the sector the private investment that is critical to its long-term health. The staffs regret that the Report does not contain a set of near-term actions to realize this strategic vision.

\section{Reforms to create competitive legal conditions conducive to attracting private} investments and the governance rules in the mining sector must be urgently pursued. In this regard, the staffs regret that the Report does not provide clear specific policy proposals based on a more systematic evaluation of past policies. The delay in adopting the new Mining Code is also regrettable. In particular, the proposed provision to zero rate gold exports could, in this period of high gold prices, help attract private investment to develop some gold deposits that would otherwise not be feasible. However, the Kyrgyz authorities have taken decisions that, once implemented, will significantly improve the governance environment of the mining sector. In particular, removing the regulatory functions for the gold mining sector from Kyrgyzaltyn, the state owned company that is the largest domestic shareholder in gold mining ventures in the country, and the decision to adopt the Extractive Industries Transparency Initiative, are very commendable steps. The Report could fruitfully have noted these developments.

\section{The Participatory Process}

17. Very strong civil society interest in formulating and monitoring poverty reduction initiatives continues to characterize the NPRS process in the Kyrgyz Republic. The Report lists a number of events that have been organized by the authorities to share with civil society information on the implementation of the NPRS and seek their feedback on how the strategy

\footnotetext{
${ }^{3}$ In addition to a legal framework, prerequisites for a viable second pillar would include: fiscal room; a sizeable stock of private trustee-grade investment assets; established, independent and well-functioning regulatory systems for the banking, insurance and asset-management sectors; complete transparency; and efficient administrative systems that could, among other things, keep administrative costs low relative to earnings on the assets.
} 
may be modified to further poverty reduction objectives. In addition to such special events, participation of government officials in frequent kurultai, or public meetings, has become a regular feature of the communication between the government and the public on the NPRS. It is particularly commendable that the authorities and the parliament have sought to open up the budget process to the public. Public hearings on budget proposals have become a regular feature of the annual budget cycle and the staffs, in their discussions with NGOs, have been informed that representatives of all local communities are invited to these hearings. The NPRS was posted on the external website of the Comprehensive Development Framework (CDF) Secretariat, and regular newsletters informing of progress in implementation is also posted there. The Annual Progress Report will also be posted on the external website of the CDF Secretariat. Data on the most important indicators, including quarterly budget execution data, is also routinely available to the public.

18. Donor coordination has improved significantly International donors are very actively involved in all aspects of the poverty reduction strategy and many areas are characterized by the involvement of multiple donors. Although the Kyrgyz authorities have also made efforts to coordinate the work of donors, the significant recent improvements have resulted largely from donors' initiatives. The Kyrgyz Republic was chosen as a pilot country at the Rome High Level Forum on Harmonization (of Donor Assistance) and donors have made significant efforts to fulfill their obligations thereunder. Guided by a Steering Committee of Donors and the Government chaired by a Vice Prime Minister, and led by a Working Group chaired by the Ministry of Finance, key efforts in donor coordination include work in progress to harmonize financial management and procurement procedures, and coordination in developing sectoral strategies, notably in education, energy, health, SME development and governance. In addition, the Asian Development Bank and the World Bank, the two largest donors active in the public investment program, recently conducted a joint review of their portfolios to better mesh their activities with the country's priorities. A donor website has also been set up to share readily information on the activities of all donors ( http://www.donors.kg ). Work on policy harmonization is also underway in a number of sectors, including governance, education and health. Much work is also needed to improve coordination within the Government if harmonization efforts are to achieve their full effect. In particular, closer coordination between the Ministry of Finance and the President's Administration vis-à-vis the interface between the $\mathrm{CDF} / \mathrm{NPRS}$ and the MTBF is essential, as is improved coordination between line Ministries, the Ministry of Finance, and project implementation units.

\section{TARGETS, INDICATORS AND MONITORING}

\section{The core NPRS indicators are being monitored with involvement of public agencies and civil society, providing an initial baseline for evaluation of NPRS} implementation. While core indicators are consistent with the present monitoring capacity, their gradual expansion along the lines suggested in the first JSA will allow the government to evaluate and adjust the NPRS policies in a more informed manner. In this process, particular attention will need to be given to greater disaggregation to capture rural urban inequities, regional differences, income disparities, gender imbalance, and the more comprehensive review of public expenditure data. The Report could have discussed plans on this front in a 
more balanced way, including a summary of ongoing work to strengthen the monitoring and evaluation system itself. For instance, such improvements seem to be possible on a fast track concerning the health sector indicators, given that the Health Policy Unit of the Ministry of Health has already initiated the collection of a very comprehensive list of indicators that pertain to health outcomes. Similarly, in addition to indicators that measure the effectiveness and efficiency of service delivery, it is very important that health care financing numbers in terms of categories of insured populations, especially vulnerable groups, is tracked on a more systematic basis. Finally, monitoring and evaluation system could be expanded to track both health and education sector allocations from categorical grants since these funds are key to delivering basic health and education services at the oblast level.

\section{RISKS TO THE STRATEGY}

\section{The risks to the poverty reduction strategy identified in the JSA of the NPRS}

remain valid. The Kyrgyz Republic's high level of external debt makes it critical for it to attract private investment, which, in turn, will allow it to grow out of poverty. However, a combination of external and home-made trade barriers, the difficult investment climate, and the vulnerability to exogenous shocks - related both to economic factors and natural calamities and weather-constrain the Kyrgyz Republic's attractiveness as an investment destination. In addition, in the period ahead, achieving political consensus on sound macroeconomic policies and difficult structural reforms will be particularly challenging in light of the uncertainties associated with the parliamentary elections in February 2005 and the presidential elections in October 2005.

\section{The Kyrgyz Republic must pay greater attention to mobilizing grant assistance} from its external donors. Even under the baseline scenario, achieving the Millennium Development Goals could be elusive without a substantial increase in grant assistance from donors. In the event of external shocks, such grant assistance will be necessary to prevent a reversal in the recent positive trends in poverty reduction. The Kyrgyz authorities have expressed an interest in holding a Consultative Group meeting with international donors later this year and the staffs urge them to use the opportunity to discuss with donors their assistance requirements in the event of external shocks.

22. Despite welcome recent signs of improvement, weak capacity remains a risk to the successful implementation of the NPRS. Sound macroeconomic policy implementation in the last few years, the considerable local initiative devoted to improving the investment climate, progress with institutionalizing the MTBF, and several other welcome developments point to a steady increase in the capacity to develop and implement policy reforms in the country. Nevertheless, in several branches of government, especially at the local government level, serious capacity constraints do threaten successful implementation of the NPRS. The staffs urge the Kyrgyz authorities to continue their already successful efforts to build capacity within the government. As will be highlighted by the World Bank's forthcoming country economic study on the growth and trade nexus in the Kyrgyz economy, an equally important issue in the development agenda is strengthening enterprise capability and productivity. 


\section{Conclusions}

23. A fuller and more critical assessment of progress thus far and greater attention to updating key elements of the strategy would have been desirable. The Report generally provides a lengthy list of measures that have been implemented in the various areas. However, it fails to provide sufficient analysis regarding the achievements and shortfalls experienced to date in implementing the NPRS priorities. In the absence of such an analysis, there is inadequate attention devoted to addressing any weaknesses in the original NPRS policies. In addition, in certain critical areas such as agriculture, the Report does not make any headway in addressing the shortcomings noted in the JSA of the NPRS. Looking forward, it would be useful for the authorities to evaluate the potential effects of regional trade initiatives on economic growth and to discuss the effects in the next Progress Report.

24. The staffs welcome the work initiated to improve costing and prioritization and poverty analysis. The first JSA had noted the very significant weaknesses in costing, prioritization and sequencing and the staffs had noted that such weaknesses marred an otherwise appropriate policy agenda. There is now evidence that the authorities have begun work to address this concern, although much still remains to be done. Similarly, the JSA of the NPRS had identified weaknesses in the analysis of poverty data. The staffs welcome the efforts that are being made to address this concern, including through improving the coverage and methodology of the household survey, as discussed in the next section. The staffs also commend the authorities' efforts to explore both the links between the implementation of the Millennium Development Goals (MDGs) and the NPRS, and the mechanisms for monitoring and evaluating the MDG indicators.

\section{Overall, the Kyrgyz authorities have made significant strides in implementing} their poverty reduction strategy. This is evident in the positive macroeconomic outcomes of the last four years as well as the better than anticipated progress on reducing poverty levels. The improvements evident in the MTBF in improving costing and prioritization, which lie at the heart of the NPRS process, are particularly notable. However, the country's economic situation remains fragile and it cannot afford a let up in the implementation of sound macroeconomic policies and structural reforms. The staffs also note that the Report does not fully reflect the progress and constraints in implementing and enhancing the poverty reduction strategy. In this regard, the staffs note that a concise and candid reflection in future Progress Reports of the state of play regarding the implementation of the NPRS must be an important element of the government's communication strategy with the public, if it is to successfully build broad-based support for its poverty reduction efforts.

26. The staffs of IDA and the IMF consider that the Kyrgyz Republic's efforts toward implementation of its poverty reduction strategy provide sufficient evidence for its continuing commitment to poverty reduction, and therefore the strategy continues to provide a credible framework for Bank and Fund concessional assistance. The staffs recommend that the respective Executive Directors of the World Bank and the IMF reach the same conclusion. 